\title{
Unexpected cause and successful management of typical urinary tract infection symptoms: Questions
}

\author{
Demet Alaygut ${ }^{1}$ (D) • Özgür Özdemir-Şimşek ${ }^{1} \cdot$ Fatma Ceren Sarıoglu $^{2} \cdot$ Seçil Arslansoyu-Çamlar ${ }^{1} \cdot$ Fatma Mutlubaş $^{1}$. \\ Belde Kasap-Demir ${ }^{3}$
}

Received: 3 April 2021 / Accepted: 20 April 2021 / Published online: 6 May 2021

(C) IPNA 2021

Keywords Child $\cdot$ Fever $\cdot$ Abdominal pain $\cdot$ Leukocytosis $\cdot$ Pyuria

\section{Case}

A 6-year-old girl was brought with fever, vomiting, and burning pain while urinating 3 days before. It was learned that amoxicillin-clavulanate treatment was initiated with the initial diagnosis of urinary tract infection, but persistent fever $\left(39^{\circ} \mathrm{C}\right)$, weakness, nausea, vomiting, deficient oral intake, flank pain, and widespread abdominal pain continued despite the treatment. Her personal and family history were unremarkable. A history of urinary tract infection was also not specified. Physical examination findings at admission were as follows: body weight: $18 \mathrm{~kg}$ (50-75\%tile), height: $112 \mathrm{~cm}$ (50-75\%tile), body temperature: $38.7{ }^{\circ} \mathrm{C}$, blood pressure: $100 / 60 \mathrm{mmHg}$, heart rate: $148 \mathrm{bpm}$, and respiratory rate: $24 / \mathrm{min}$. The patient was cooperative and oriented. The patient was dehydrated with sunken eyeballs, and tenderness on the left costovertebral angle and in the left lower abdominal quadrant on palpation. Physical examination of other of organ systems was within normal limits. Selected laboratory test

The answers to these questions can be found at https://doi.org/10.1007/ s00467-021-05091-y.

Demet Alaygut

alaygutdemet@gmail.com

1 Department of Pediatric Nephrology, University of Health Sciences Tepecik Training and Research Hospital, Konak, Izmir, Turkey

2 Department of Radiology, Division of Pediatric Nephrology, University of Health Sciences Tepecik Training and Research Hospital, Konak, Izmir, Turkey

3 Faculty of Medicine, Department of Pediatric Nephrology and Rheumatology, Izmir Katip Celebi University, Izmir, Turkey results were as follows: WBC: $21,100 / \mathrm{mm}^{3}(\mathrm{~N}: 4200$ 10,500), ANS: $18,300 / \mathrm{mm}^{3}$ (N: 2000-6900), Hb: $12 \mathrm{~g} /$ $\mathrm{dL}$ (N: 12.2-16.2), platelet counts: $174,000 / \mathrm{mm}^{3}$, procalcitonin: $5.25 \mu \mathrm{g} / \mathrm{L}(\mathrm{N}: 0.04-0.1), \mathrm{CRP}: 290 \mathrm{mg} / \mathrm{L}$ (n: 0-5), urea: $19 \mathrm{mg} / \mathrm{dL}$ (n: $10-38$ ), creatinine: $0.5 \mathrm{mg} /$ dL, fibrinogen: $768 \mathrm{mg} / \mathrm{dL}$ (n: 170-420), D-dimer: 1620 $\mu \mathrm{g} / \mathrm{L}$ (n: $0-440$ ). Liver function test results and electrolytes were within normal limits. In urinalysis, density: 1018, pH: 6.5 , protein +1 , leukocytes +3 , erythrocytes +3 , nitrite $(-)$, abundant leukocytes, and bacteria were seen in all microscopic images. Size, echogenicity, and parenchymal thickness of the right kidney on ultrasonography were normal, while the left kidney was edematous, enlarged with heterogeneously contrasting parenchyma. Any pathological finding was not detected in the mesentery, except for lymph nodes with increased reactive appearance and a short diameter not exceeding $1 \mathrm{~cm}$. The COVID-19 PCR test result was negative. Direct urinary system radiography was not remarkable.

An abdominal MRI was performed in order to distinguish other possible pathologies due to persistent high fever, abnormal physical examination findings, and increased levels of acute phase reactants. In contrast-enhanced abdomen MRI T1-weighted fat-suppressed coronal sections, the right kidney was within normal limits, the left kidney was increased in size, and the parenchyma was markedly edematous. Nonenhancing area in the upper pole of the left kidney and millimetric hypointense air signals in the periphery of this area were observed (Fig. 1a, yellow arrow). There were nonenhancing patchy areas in the middle and lower poles, and diffusion restriction was not observed in non-enhancing areas. Lymphadenopathies were observed adjacent to the renal hilus and the short axis of the larger lymph node was $12 \mathrm{~mm}$ in diameter (Fig. 1b). 
Fig. 1 a Non-enhancing area in the upper pole of the left kidney and millimetric hypointense air signals in the periphery of this area. b Lymphadenopathies were observed adjacent to the renal hilus and the short axis of the larger lymph node was $12 \mathrm{~mm}$ in diameter

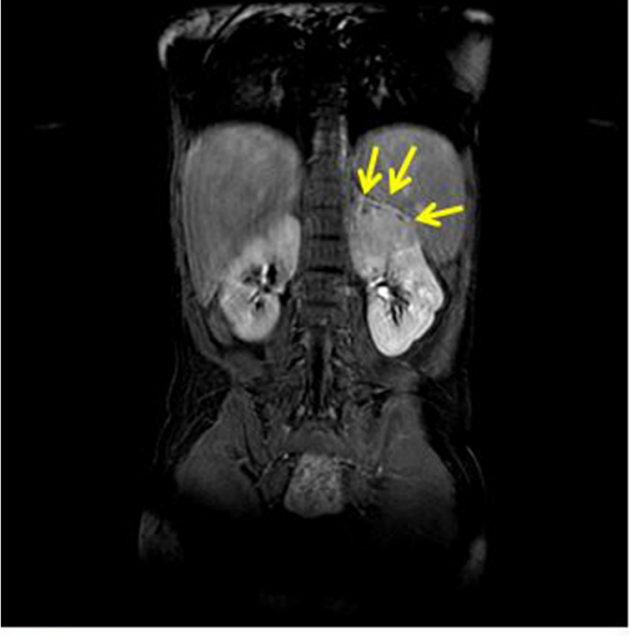

a

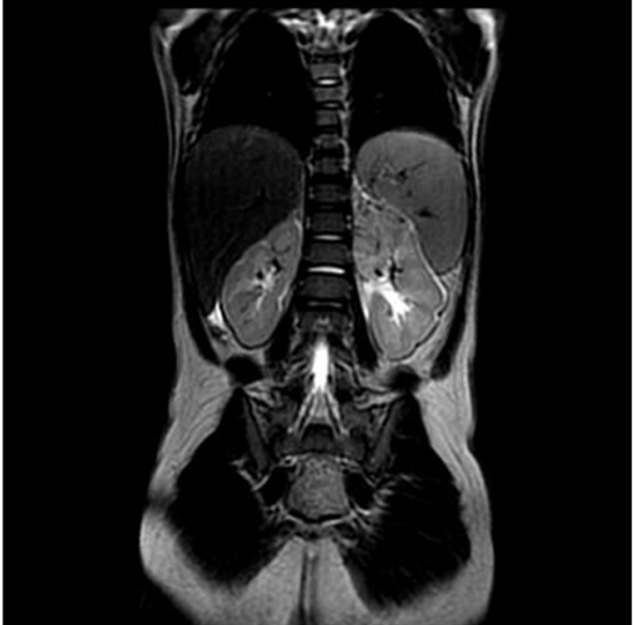

b

\section{Questions}

1. What is your probable diagnosis for this patient? Which diagnosis is supported by the finding indicated in the scans?

2. What conditions should be considered in differential diagnosis? How should the patient be managed?

\section{Declarations}

Conflict of interest The authors declare no competing interests.

Publisher's note Springer Nature remains neutral with regard to jurisdictional claims in published maps and institutional affiliations. 